\title{
FAKTOR-FAKTOR YANG MEMPENGARUHI MINAT NASABAH TERHADAP PRODUK RAHN PADA PEGADAIAN SYARIAH
}

\author{
Amanda Veronica, Muhammad Iqbal Fasa, Suharto \\ Universitas Islam Negeri Raden Intan Lampung \\ Email: amandavero06@gmail.com; miqbalfasa@radenintan.ac.id; \\ Prof.suharto@radenintan.ac.id
}

\begin{abstract}
The growing development of sharia-related products that are increasingly crowded in Indonesia also has an effect on the business development of PT Pegadaian (Persero). Therefore, PT Pegadaian (Persero) also issued a new product that smelled of sharia under the name Pegadaian Syariah. The legal basis for the establishment of Sharia Pawnshops is PP No. 103 dated November 102000 and Fatwa DSN No. 25 / DSN-MUI / III / 2002 concerning Rahn. For this reason, this study aims to examine and analyze the effect of promotions, prices and loan disbursement procedures on customer interest in using rahn products in Islamic pawnshops. This research uses quantitative research. The type of data used in this research is primary data. Primary data is data that comes from the original source or the first one that comes from a questionnaire. Based on the analysis and data processing above, the results obtained include promotion variables that affect customer interest, price variable affects customer interest and loan disbursement procedure variables also affect customer interest.
\end{abstract}

Keywords: Customer Interest, Promotion, Price / Cost, Fund Disbursement Procedure, Sharia Pawnshop 


\begin{abstract}
ABSTRAK
Pertumbuh kembangan produk-produk berbau syariah yang kian ramai di Indonesia berpengaruh pula dengan perkembangan bisnis PT Pegadaian (Persero). Oleh karena itu PT Pegadaian (Persero) pula mengeluarkan produk baru yang berbau syariah dengan nama Pegadaian Syariah. Landasan hukum berdirinya Pegadaian Syariah adalah PP Nomor 103 Tanggal 10 November 2000 serta Fatwa DSN No 25/DSN-MUI/III/2002 tentang Rahn. Untuk itu penelitian ini bertujuan menguji dan menganalisis pengaruh promosi, harga dan prosedur pencairan pinjaman terhadap minat nasabah menggunakan produk rahn pada pegadaian syariah. Penelitian ini menggunakan penelitian yang bersifat kuantitatif. Jenis data yang digunakan dalam penelitian ini adalah data primer. Data primer adalah data yang berasal dari sumber asli atau pertama yang berasal dari kuesioner. Berdasarkan analisis dan pengolahan data diatas maka hasil yang didapatkan diantaranya variabel promosi berpengaruh terhadap minat nasabah, variabel harga berpengaruh terhadap minat nasabah dan variabel prosedur pencairan pinjaman juga berpengaruh terhadap minat nasabah.
\end{abstract}

Kata Kunci : Minat Nasabah, Promosi, Harga/Biaya, Prosedur Pencairan Dana, Pegadaian Syariah 


\section{PENDAHULUAN}

Dalam kehidupan sehari-hari, uang selalu dibutuhkan untuk membeli maupun membayar berbagai kebutuhan yang diperlukan, namun terkadang kebutuhan yang diperlukan tidak dapat dipenuhi karena kendala uang yang dimiliki. Dengan demikian tak jarang masyarakat memilih untuk menjual suatu aset atau barang bernilai miliknya. Namun hal tersebut berisiko barang yang telah dijual akan hilang dan sulit untuk kembali. Untuk itu dalam mengatasi permasalahan di atas maka masyarakat dapat meminjamkan barang bernilai nya pada lembaga tertentu di mana kebutuhan dana dapat terpenuhi dengan tanpa kehilangan barang miliknya.

Dengan tujuan dan penggambaran tersebut maka hadirlah lembaga keuangan yang bernama pegadaian. Pada pegadaian masyarakat dapat melakukan kegiatan bernama gadai di mana masyarakat dapat memperoleh pencairan dana dengan meminjamkan barang bernilai miliknya sebagai jaminan yang nantinya dapat ditebus kembali.

Secara generik pegadaian adalah aktivitas meminjamkan barang-barang berharga kepada pihak eksklusif guna memperoleh sebesar uang \& barang yang dijaminkan akan ditebus kembali sesuai menggunakan kesepakatan antara nasabah menggunakan lembaga gadai. ${ }^{1}$ Perusahaan pegadaian merupakan forum keuangan yang menyiapkan fasilitas pinjaman dengan agunan tertentu. Agunan nasabah tersebut digadaikan, lalu dilakukan perhitungan oleh pihak pegadaian agar mengetahui besaran nilai agunan. Besar nilai agunan akan menghasilkan besaran jumlah pinjaman. ${ }^{2}$ Saat ini ramai berdiri lembaga keuangan di tengah masyarakat seperti bank atau juga non bank yang melakukan aktivitasnya dengan memberikan dana pada masyarakat yang membutuhkan, tanpa terkecuali lembaga keuangan syariah non bank seperti Pegadaian Syariah. ${ }^{3}$

\footnotetext{
${ }^{1}$ Kasmir. Bank dan Lembaga Keuangan Lainnya Edisi Revisi 2014. (Jakarta : PT Raja Grafindo Persada).

2 Soemitra, Andri. Bank dan Lembaga Keuangan Syariah: Edisi Pertama. 2009. (Jakarta : Prenadamedia Group).

3 Laila Maghfirah, Ridwan Nurdin, dan Korespondensi Penulis, "Analisis Faktor-Faktor yang Mempengaruhi Minat Nasabah Menggunakan Produk Rahn pada Pegadaian Syariah (Studi Kasus pada Kantor Pusat Pegadaian Syariah Kota Banda Aceh)," Jurnal Ilmiah Mahasiswa Ekonomi Islam, 2019,
} 
Kehadiran pegadaian syariah membawa pengaruh positif dalam kemajuan lembaga keuangan. Perkembangan nya yang semakin maju pula dipengaruhi karena sebagian besar masyarakat di Indonesia yang beragama Islam sehingga hadirnya pegadaian syariah dapat diterima dengan mudah. Hal yang sebagai upaya dari pegadaian syariah agar memikat minat nasabahnya dalam memakai jasa layanan pegadaian syariah di antaranya produk yang dipasarkan oleh pegadaian syariah ini memiliki ciri seperti, tidak mempraktikkan sistem bunga pada semua kegiatan dikarenakan riba, tetapkan uang menjadi sistem tukar bukan menjadi komoditas yang diperjualkan, dan yang tanpa terlewat keuntungan didapat dari porto jasa simpan barang yaitu menjalankan porto pemeliharaan atas barang yang digadaikan seperti yang telah diwajibkan oleh Dewan Syariah Nasional ${ }^{4}$.

Pertumbuh kembangan produkproduk berbau syariah yang kian ramai di Indonesia berpengaruh pula dengan perkembangan bisnis PT Pegadaian

<http://www.jim.unsyiah.ac.id/EKI/article/view/130 22>.

${ }^{4}$ Maghfirah, Nurdin, dan Penulis.
(Persero). Oleh karena itu, PT Pegadaian (Persero) pula mengeluarkan produk baru yang berbau syariah dengan nama Pegadaian Syariah. Landasan hukum berdirinya Pegadaian Syariah adalah PP Nomor 103 Tanggal 10 November 2000 serta Fatwa DSN No 25/DSNMUI/III/2002 tentang Rahn. Kemunculan Pegadaian Syariah mulanya dipacu karena perkembangan dan kesuksesan lembaga lembaga keuangan layaknya Bank Syariah, Asuransi Syariah, \& lainnya lagi. Daripada itu pula dipondasikan oleh keperluan warga Indonesia akan munculnya suatu institusi pegadaian yang memberlakukan prinsip-prinsip keislaman ${ }^{5}$.

Melihat perkembangan pegadaian syariah yang semakin memberikan produk inovatif dan menarik tidak menutup kemungkinan bagi masyarakat untuk menggunakan produk-produk dalam pegadaian syariah. Melihat dari kesesuaian syariat Islam, inovasi

5 Siti Hadijah, "Faktor-Faktor Yang Mempengaruhi Keputusan Nasabah Menggunakan Jasa Pegadaian Syariah Kantor Cabang Pegadaian Syariah (KCPS) Denpasar," Jurnal Ekonomi dan Bisnis, 5.1 (2015). 
produk yang menarik, serta hal lainnya menjadikan pegadaian syariah tidak hanya digunakan oleh masyarakat yang membutuhkan pendanaan saja melainkan terdapat produk lainnya yang lebih beragam sesuai kebutuhan nasabah.

Secara teoritis dalam menentukan badan atau institusi pemberi kredit, masyarakat pasti meninjau dan memperhitungkan beberapa faktor-faktor guna mendapat keputusan untuk menggunakan pelayanan jasa pegadaian. Diantara faktor-faktor yang memberi pengaruh masyarakat dalam penggunaan jasa ialah salah satunya kualitas layanan ${ }^{6}$. Dewasa ini kian maraknya lembaga keuangan perbankan syariah yang memiliki jasa rahn, karenanya daya saing meningkat antara satu lembaga dengan lembaga lainnya. Semakin poly pesaing semakin poly juga referensi masyarakat dalam menentukan produk yang sinkron sesuai angannya. Sebab itu, strategi menjadi faktor yang genting untuk

${ }^{6}$ Hadijah. menciptakan suatu upaya supaya tetap bertahan dan siap bersaing ${ }^{7}$.

Secara umum, penelitian ini terfokus pada faktor-faktor yang dapat mempengaruhi minat nasabah dalam memakai produk rahn dari pegadaian syariah. Hal ini dapat dilihat dan ditinjau dari promosi, harga/biaya dan prosedur pencairan pinjaman dalam memberikan minat dan kesan tertarik pada masyarakat atau nasabah.

\section{Tinjauan Pustaka}

Pengertian Pegadaian

Pegadaian ialah tempat di mana masyarakat yang memerlukan uang tunai dapat hadir meminjam uang melalui barang-barang pribadi sebagai agunannya. ${ }^{8}$ Secara generik penjelasan usaha gadai yakni aktivitas meminjamkan barang-barang bernilai pada pihak tertentu, supaya mendapatkan sebesar uang dan barang yang dijaminkan dan diambil kembali sesuai

\footnotetext{
${ }^{7}$ Maghfirah, Nurdin, dan Penulis.

${ }^{8}$ Muhammad. 2020. Bank dan Lembaga Keuangan Lainnya. (Depok : Rajawali Pers). h, 226
} 
dengan kesepakatan antara nasabah menggunakan lembaga gadai. ${ }^{9}$

Berdasarkan dari penjelasan diatas maka bisa ditarik bahwa karakteristik menurut bisnis gadai adalah seperti:

1. Adanya barang bernilai yg bisa digadaikan.

2. Besaran jumlah pinjaman sesuai menggunakan nilai jumlah barang yang digadaikan \& nantinya bisa ditebus kembali.

\section{Pengertian Rahn (Gadai)}

Rahn merupakan perjanjian penyerahan barang sebagai jaminan sehingga orang yang bersangkutan boleh mengambil utang. ${ }^{10}$ Ar-Rahn ialah kesepakatan pemberian barang guna sebagai agunan dari fasilitas pembayaran yang diberlakukan.

Perjanjian gadai dalam Islam (rahn) adalah perjanjian meyimpan suatu benda sebagai agunan utang. Rahn ialah akad utang piutang dengan menjadikan barang yang memiliki nilai jual sebagai

\footnotetext{
${ }^{9}$ Kasmir. 2016. Bank dan Lembaga Keuangan Lainnya Edisi Revisi 2014. (Jakarta : PT Raja Grafindo Persada). h, 231

10 Mulazid, Ade Sofyan. 2016. Kedudukan Sistem Pegadaian Syariah Edisi Pertama. (Jakarta : Prenadamedia Group). h, 4
}

agunan dalam pemberian pinjaman. Adapun persamaan gadai dengan rahn antara lain: ${ }^{11}$

1. Hak gadai berlaku atas pinjaman uang

2. Memiliki agunan sebagai jaminan barang

3. Dilarang merogoh daya guna atas benda yang digadaikan

4. Biaya benda yang digadaikan ditanggungi pada penyedia gadai

5. Jika limit ketika pinjaman telah usai, benda yang dijual bisa dipasarkan atau dilelang

\section{Berdirinya Pegadaian Syariah}

Pegadaian syariah berdiri lantaran adanya kolaborasi menggunakan Bank Muamalat Indonesia. Bank Muamalat Indonesia pun masih belum memiliki keahlian manajemen dalam hal penaksiran benda, tetapi dalam halnya pegadaian telah mempunyai pakar penghitung benda hanya saja ketersediaan dana yang masih minimum. Karena nya, berdasarkan itu perlu hadirnya kolaborasi dari pegadaian dan bank

11 Op cit. Muhammad. Bank dan Lembaga Keuangan Lainnya. h, 229 
mempergunakan prinsip bagi hasil. Sifat bisnis pegadaian syariah pada dasarnya meyiapkan layanan untuk kegunaan umum sekaligus menghasilkan laba atas prinsip pengelolaan. ${ }^{12}$

Pada dasarnya pegadaian memiliki tujuan-tujuan pokok sesuai yang tercantum pada PP No.103 tahun 2000 yaitu:

1. Turut menaikkan kesejahteraan masyarakat khususnya golongan menengah ke bawah berdasarkan penyediaan uang atas dasar hukum gadai dan jasa di lembaga pendanaan lainnya menurut ketentuan peraturan perundangundangan yang ditetapkan.

2. Turut menjalankan dan menunjang aplikasi kebijakan dan program pemerintah pada kagiatan ekonomi dan pembangunan nasional dalam generik dari penyaluran dana pinjaman kepada rakyat atas dasar hukum gadai.

3. Mencegah dan memberantas kegiatan pegadaian gelap, ijon

12 Op cit. Muhammad. Bank dan Lembaga Keuangan Lainnya. h, 228 dan pinjaman tidak wajar lainnya. ${ }^{13}$

\section{Minat}

Menurut Kamus Besar Bahasa Indonesia, minat merupakan kecenderungan hati yang tinggi terhadap sesuatu; gairah; keinginan. ${ }^{14}$ Minat merupakan keinginan ataupun dorongan seseorang berdasarkan hati nurani nya untuk melakukan atau mengikuti sesuatu yang diinginkan berdasarkan apa yang diperlukan atau sekedar diinginkan.

\section{Faktor-faktor yang Mempengaruhi Minat}

Berdasarkan kajian dan juga teori terhadap hasil dari penelitian sebelum ini bahwa ada banyak faktor yang mempengaruhi minat nasabah dalam menggunakan produk rahn di pegadaian syariah. Akan tetapi dalam hal ini peneliti ingin lebih memfokuskan, menguji dan meneliti kembali faktor promosi, harga/biaya dan prosedur pencairan pinjaman dalam memberikan minat dan kesan tertarik pada masya-

https://peraturan.bpk.go.id/Home/Details/53682/p p-no-103-tahun-2000

${ }^{14}$ https://kbbi.web.id/ 
rakat atau nasabah terkait produk rahn di Pegadaian Syariah. Untuk itu peneliti akan membahas pengertian dari masing-masing faktor yang akan diuji.

\section{Promosi}

Promosi ialah aktivitas pemasar dalam memperdagangkan dan merayu para target pembeli agar menghipnotis pendapat mereka atau menghasilkan suatu respon ${ }^{15}$.

Tujuan dari promosi ialah memperluaskan informasi produk kepada target pemasaran; menerima peningkatan penjualan dan laba; menerima pelanggan baru dan menjaga keutuhan pelanggan; menjaga kekonsistenan penjualan saat terjadi lemah pasar; memberikan pembedaan dan mengunggulkan produk daripada produk pesaing; mengukir citra produk di pandangan konsumen sesuai apa yang diekspektasikan ${ }^{16}$.

\footnotetext{
${ }^{15}$ Maghfirah, Nurdin, dan Penulis.

16 Zaki Mubarak dan Indriani Windasari, "Faktor-faktor yang mempengaruhi perilaku konsumen dalam memilih pegadaian syariah di Kota Banjarmasin," At-Taradhi: Jurnal Studi Ekonomi, 4.1 (2014).
}

Harga/Biaya

Harga ialah total seluruh nilai yang disajikan oleh pelanggan guna memperoleh kemanfaatan dari mendapatkan atau menggunakan suatu produk juga jasa. Harga merupakan penunjang utama yang mempengaruhi pilihan para konsumen ${ }^{17}$.

\section{Prosedur Pencairan Dana / Pinjaman}

Prosedur pencairan pinjaman yakni proses atau langkah-langkah yang berhubungan menggunakan bagaimana warga mendapat pinjaman ketika sebagai nasabah pada suatu lembaga keuangan ${ }^{18}$.

\section{Metode Penelitian}

Jenis dan Sifat Penelitian

Penelitian ini memakai penelitian yang bersifat kuantitatif pada mana penelitian kuantitatif merupakan suatu metode penelitian dengan karakteristik induktif, objektif dan ilmiah pada data yang dihasilkan seperti angka-angka (score, nilai) atau pernyataan-pernya-

\footnotetext{
${ }^{17}$ Mubarak dan Windasari.

${ }^{18}$ Maghfirah, Nurdin, dan Penulis.
} 
taan yang di nilai, dianalisis dengan analisis statistik ${ }^{19}$.

\section{Sumber Data}

Jenis data yang digunakan dalam penelitian ini adalah data primer. Data primer merupakan data yang berasal berdasarkan sumber asli atau pertama. Data ini wajib dicari melalui narasumber atau dalam kata teknisnya responden, yaitu target yang kita jadikan objek penelitian atau target yg dijadikan sebagai wahana mendapat warta ataupun data ${ }^{20}$. Data primer yang dihasilkan penelitian ini adalah berasal dari kuesioner.

\section{Teknik Pengumpulan Data}

Teknik pengumpulan data pada penelitian ini menggunakan kuisioner. Kuisioner atau daftar isian ialah serangkaian pertanyaan yang terbentuk secara sistematis dan standar sehingga

19 Iwan Hermawan, Metodologi Penelitian Pendidikan (Kualitatif, Kuantitatif dan Mixed Method) (Hidayatul Quran, 2019).

20 Arti Lina Rahmawati dan Kurniawati Mutmainah, "Analisis Faktor-faktor yang Mempengaruhi Permintaan ( Studi Kasus Pada Pegadaian Syariah Kebondalem Magelang )," 2020. pertanyaan yang sama dapat diajukan terhadap setiap responden. ${ }^{21}$

\section{Metode Analisis Data}

Analisis deskriptif ialah bentuk analisa data penelitian guna menguji generalisasi hasil penelitian yang berdasarkan atas sebuah sampel. Analisa naratif ini dilakukan berdasarkan pengujian hipotesa deskriptif. Hasil analisanya adalah apakah hipotesa penelitian dapat digeneralisasikan atau malah tidak ${ }^{22}$.

\section{HASIL DAN PEMBAHASAN}

Berdasarkan hasil kuesioner yang diberikan kepada 44 orang responden, analisis latar belakang responden berdasarkan jenis kelamin, usia dan profesi. Data yang dihasilkan bahwa responden yang paling banyak adalah responden dengan jenis kelamin wanita dengan perolehan sebesar $63,6 \%$ dan laki-laki sebesar $36,45 \%$. Pada presentase usia maka responden dengan rentan usia 20-30 tahun paling mendo-

21 J Supranto. Statistik Teori dan Aplikasi. (Jakarta: Erlangga)

22 Lenni Masnidar Nasution, "Statistik deskriptif," Hikmah, 14.1 (2017), 49-55. 
minasi yaitu mencapai $86,4 \%$ dan $93,2 \%$ responden yang berprofesi responden yang berusia kurang dari 20 sebagai pelajar/mahasiswa dan 6,8\% tahun sebanyak 13,6\%. Sedangkan sebagai pekerja. untuk presentase profesinya sebanyak

\begin{tabular}{|c|c|c|c|}
\hline No. & Jenis Kelamin & Frekuensi & Presentase \\
\hline 1 & Laki-laki & 16 & $36,4 \%$ \\
\hline 2 & Perempuan & 28 & $63,6 \%$ \\
\hline \multicolumn{2}{|r|}{ Jumlah } & 44 & $100 \%$ \\
\hline
\end{tabular}

Tabel 1. Responden berdasarkan jenis kelamin.

Berdasarkan tabel 1 diatas dapat responden dengan jenis kela min lakidiketahui bahwa terdapat 28 responden laki sebanyak 16 responden dengan berjenis kelamin perempuan dengan perolehan presentase 36,4\%. presentase sebesar $63,6 \%$ sedangkan

\begin{tabular}{|c|c|c|c|}
\hline No. & Usia & Frekuensi & Presentase \\
\hline 1 & $<20$ Tahun & 6 & $13,6 \%$ \\
\hline 2 & $20-30$ Tahun & 38 & $86,4 \%$ \\
\hline 3 & $31-40$ Tahun & - & - \\
\hline 4 & $>40$ Tahun & - & $\mathbf{1 0 0} \%$ \\
\hline \multicolumn{2}{|c|}{} \\
\hline
\end{tabular}

Tabel 2. Responden berdasarkan usia.

Dari tabel 2, dapat diketahui bahwa sebagian besar usia responden adalah antara 20-30 tahun, yaitu sebanyak 38 responden atau sebesar $86,4 \%$.
Sedangkan terdapat 6 responden yang berusia $<20$ tahun atau hanya sebesar $13,6 \%$. 


\begin{tabular}{|r|c|c|c|}
\hline \multicolumn{1}{r|}{ o. } & Profesi & Frekuensi & Presentase \\
\hline 1 & Pelajar/mahasiswa & 41 & $93,2 \%$ \\
\hline 2 & Pekerja & 3 & $6,8 \%$ \\
\hline \multicolumn{2}{r|}{ Jumlah } & $\mathbf{4 4}$ & $\mathbf{1 0 0} \%$ \\
\hline
\end{tabular}

Tabel 3. Responden berdasarkan profesi nya.

Pada tabel 3 dapat dilihat bahwa responden dengan profesi sebagai pelajar/mahasiswa mendominasi dengan jumlah frekuensi sebesar 41 responden dan presentase mencapai 93,2\%. Sedangkan untuk responden dengan profesi sebagai pekerja sebanyak 3 responden dengan presentase sebesar 6,8\%.
Pada penelitian ini skala likert digunakan sebagai pengukuran besar minat nasabah dengan faktor-faktor yang disajikan menggunakan kuesioner. Di mana nantinya dari pertanyaan-pertanyaan tersebut akan dapat diukur seberapa minat masyarakat terhadap produk yang diuji.

\begin{tabular}{|c|c|c|c|}
\hline No. & Simbol & Keterangan & Skor \\
\hline 1 & STS & Sangat Tidak Setuju & 1 \\
\hline 2 & TS & Tidak Setuju & 3 \\
\hline 3 & S & Setuju & 4 \\
\hline 4 & SS & Sangat Setuju & 2 \\
\hline
\end{tabular}

Tabel 4. Skala likert yang digunakan.

Dengan menggunakan skala likert jawaban dilakukan dengan rumus pada kuesioner yang diberikan kepada sebagai berikut: nasabah maka perhitungan indeks Rumus Nilai Indeks $=(\mathrm{F} 1 \times 1)+(\mathrm{F} 2 \times 2)$ $+(\mathrm{F} 3 \times 3)+(\mathrm{F} 4 \times 4)$ 


\section{Keterangan :}

F1: frekuensi jawaban responden yang menjawab 1 (Sangat Tidak Setuju)

F2: frekuensi jawaban responden yang menjawab 2 (Tidak Setuju)
F3: frekuensi jawaban responden yang menjawab 3 (Setuju)

F4: frekuensi jawaban responden yang menjawab 4 (Sangat Setuju)

\begin{tabular}{|c|l|}
\hline Jawaban & \multicolumn{1}{|c|}{ Keterangan } \\
\hline $75 \%-100 \%$ & Sangat (Setuju, Tertarik) \\
\hline $50 \%-74,99 \%$ & Setuju atau Tertarik \\
\hline $25 \%-49,99 \%$ & Tidak Setuju atau Tidak Tertarik \\
\hline $0 \%-24,99 \%$ & Sangat (Tidak Setuju, Tidak Tertarik atau Kurang Sekali) \\
\hline
\end{tabular}

Tabel 4. Presentase nilai

Berdasarkan data diatas selanjutnya diolah dengan cara mengkalikan setiap point pada jawaban dengan bobot yang sudah ditentukan berdasarkan tabel bobot nilai.

Sebelum mendapatkan hasil interpretasi maka terlebih dahulu harus mengetahui skor tertinggi $(X)$ \& angka terendah $(Y)$ dengan rumus:

$\mathrm{Y}=$ Skor tertinggi likert $\mathrm{x}$ jumlah responden (Angka tertinggi 4)

$\mathrm{X}=$ Skor terendah likert $\mathrm{x}$ jumlah responden (Angka terendah 1)

Jumlah skor tertinggi buat item "Sangat Setuju" adalah 4 x $44=176$, sedangkan item "Sangat Tidak Setuju" merupakan 1 x $44=44$. Setelah mendapatkan hasil berdasarkan total skor responden, maka penelitian interpretasi responden merupakan output nilai yang dihasilkan dengan memakai rumus index $\%$.

Rumus Index $=$ Total skor/y x 100\%

Berdasarkan data yang didapat dari 44 responden, hasil penilaian interpretasi terhadap minat masyarakat dalam menggunakan produk Rahn dapat dilihat dari tabel berikut: 


\begin{tabular}{|c|c|c|c|}
\hline Pertanyaan & Total Skor & Hasil Rumus Index & Kategori \\
\hline 1 & 153 & $86,93 \%$ & Sangat Setuju \\
\hline 2 & 140 & $79,54 \%$ & Sangat Setuju \\
\hline 3 & 152 & $86,36 \%$ & Sangat Setuju \\
\hline 4 & 132 & $75 \%$ & Sangat Setuju \\
\hline 5 & 143 & $81,25 \%$ & Sangat Setuju \\
\hline 6 & 134 & $76,13 \%$ & Sangat Setuju \\
\hline 7 & 138 & $78,41 \%$ & Sangat Setuju \\
\hline 8 & 133 & $75,57 \%$ & Sangat Setuju \\
\hline 9 & 136 & $77,27 \%$ & Sangat Setuju \\
\hline 10 & 135 & $76,70 \%$ & Sangat Setuju \\
\hline 11 & 135 & $76,70 \%$ & Sangat Setuju \\
\hline 12 & 138 & $78,41 \%$ & Sangat Setuju \\
\hline 13 & 141 & $80,11 \%$ & \\
\hline
\end{tabular}

Tabel 5. Hasil penilaian interpretasi.

\section{SIMPULAN}

Berdasarkan analisis dan pengolahan data diatas maka bisa disimpulkan bahwa, variabel promosi berpengaruh terhadap minat nasabah dalam menggunakan suatu produk yakni pada hal ini merupakan Rahn menurut Pegadaian Syariah. Variabel harga/biaya berpengaruh terhadap minat nasabah untuk menggunakan produk Rahn dalam
Pegadaian Syariah. Variabel prosedur pencairan pinjaman juga berpengaruh terhadap minat nasabah dalam memilih produk Rahn. Secara keseluruhan, dalam pengisian kuesioner responden setuju terhadap tiga variabel yang digunakan untuk mengukur minat nasabah dalam menggunakan produk Rahn dari Pegadaian Syariah. 
Amanda Veronica, Muhammad Iqbal Fasa, Suharto 
Hadijah, Siti, "Faktor-Faktor Yang Mempengaruhi Keputusan Nasabah Menggunakan Jasa Pegadaian Syariah Kantor Cabang Pegadaian Syariah (KCPS) Denpasar," Jurnal Ekonomi dan Bisnis, 5.1 (2015)

Hermawan, Iwan, Metodologi Penelitian Pendidikan (Kualitatif, Kuantitatif dan Mixed Method) (Hidayatul Quran, 2019)

https://peraturan.bpk.go.id/Home/Details/53682/pp-no-103-tahun-2000

https://kbbi.web.id/

Kasmir. 2016. Bank dan Lembaga Keuangan Lainnya Edisi Revisi 2014. (Jakarta : PT Raja Grafindo Persada).

Maghfirah, Laila, Ridwan Nurdin, dan Korespondensi Penulis, "Analiasis Faktorfaktor yang Mempengaruhi Minat Nasabah Menggunakan Produk Rahn Pada Pegadaian Syariah (Studi Kasus pada Kantor Pusat Pegadaian Syariah Kota Banda Aceh)," Jurnal Ilmiah Mahasiswa Ekonomi Islam, 2019, 109-26 <http://www.jim.unsyiah.ac.id/EKI/article/view/13022>

Mubarak, Zaki, dan Indriani Windasari, "Faktor-faktor yang mempengaruhi perilaku konsumen dalam memilih pegadaian syariah di Kota Banjarmasin," At-Taradhi: Jurnal Studi Ekonomi, 4.1 (2014)

Muhammad. 2020. Bank dan Lembaga Keuangan Lainnya. (Depok : Rajawali Pers)

Mulazid, Ade Sofyan. 2016. Kedudukan Sistem Pegadaian Syariah Edisi Pertama. (Jakarta : Prenadamedia Group).

Nasution, A. W. (2019). Analisis_Faktor_Kesadaran_Literasi_Keuan. 7, 40-63.

Nasution, Lenni Masnidar, “Statistik deskriptif,” Hikmah, 14.1 (2017), 49-55

Rahmawati, Arti Lina, dan Kurniawati Mutmainah, “Analisis Faktor-faktor yang 
Mempengaruhi Permintaan ( Studi Kasus Pada Pegadaian Syariah Kebondalem Magelang )," 2020

Supranto, J. Statistik Teori dan Aplikasi. (Jakarta: Erlangga)

Soemitra, Andri. Bank dan Lembaga Keuangan Syariah: Edisi Pertama. 2009. (Jakarta : Prenadamedia Group). 